\title{
KELAHIRAN MUHAMMADIYAH DARI PERSPEKTIF HERMENEUTIK
}

\section{Suwarno}

Program Studi Pendidikan Sejarah, Fakultas Keguruan dan Ilmu Pendidikan (FKIP), Universitas Muhammadiyah Purwokerto. Email: suwarnopurwokerto@gmail.com

\begin{abstract}
This article discusses the birth of Muhammadiyah from a hermeneutic perspective, especially from Gadamer. Ahmad Dahlan founded Muhammadiyah on 18 November 1912 based on the knowledge of the idea of modern Islamic reform and understanding and concern about the real condition of Muslims who was hit by poverty, ignorance and backwardness. Ahmad Dahlan has a high historical awareness to change the traditions of society which were covered by the syncretic Islamic tradition that produces superstitious culture and traditionalist Islam that produces heretical and khurafat cultures towards Islamic purification and the dynamism of Islamic society. Ahmad Dahlan's historical awareness was sustained by his strong temperament, firm stance and his courage to break the tradition of perverts.
\end{abstract}

Keywords: Muhammadiyah, Ahmad Dahlan, hermeneutic

\section{PENDAHULUAN}

Pembicaraan tentang Islam di Indonesia pasti tidak dapat dilepaskan dari dua organisasi, Muhammadiyah yang didirikan oleh Ahmad Dahlan pada 1912 dan Nahdlatul Ulama (NU) yang berdiri pada 1926. Muhammadiyah dan NU mewakili dua kutub yang berbeda. Muhammadiyah mewakili kutub modernis atau reformis, yakni golongan pembaru Islam modern, sebaliknya NU mewakili kutub tradisionalis, ialah golongan pembela dan pemelihara tradisi Islam. ${ }^{1}$ Tulisan ini hanya terfokus pada Muhammadiyah.

Menurut M. Amien Abdullah, Muhammadiyah sejak awal didirikan, telah memerankan diri sebagai Lembaga Swadaya Masyarakat (LSM) atau NonGovernmental Organization (NGO) yang terus terlibat aktif dalam pengembangan dan pemberdayaan masyarakat di bidang sosial, budaya, pendidikan, pelayanan kesehatan, ekonomi, dan lain-lain secara mandiri sambil bekerja sama dengan pemerintah. ${ }^{2}$

${ }^{1}$ Lihat dalam R. William Liddle, Leadership and Culture in Indonesian Politics, (Sydney: Allen \& Unwin, 1996), hlm. 73.

${ }^{2}$ M. Amin Abdullah, "Muhammadiyah's Experience in Promoting A Civil Society", dalam Profetika, Jurnal Studi Islam, Vol. 2, No. 1 Januari 2000. Surakarta: Program Magister Studi Islam Universitas Muhammadiyah Surakarta. 
Terdapat tiga garapan utama sebagai ranah aktivitas dakwah Muhammadiyah dan telah menjadi semacam brand oganisasi ini. Pertama, schooling, yang bermakna bidang pendidikan dengan cara mendirikan sekolah-sekolah modern. Kedua, healing, yakni bidang pelayanan sosial dengan mendirkan balai pengobatan, poliklinik dan rumah sakit. Ketga, feeding, yang artinya bergerak di bidang sosial menyantuni anak yatim dan fakir miskin dengan cara mendirikan panti asuhan anak yatim dan panti jompo. ${ }^{3}$

Salah satu karakter Muhammadiyah yang paling menonjol sejak awal kelahiran, pertumbuhan dan perkembangannya, adalah posisi organisasi ini sebagai gerakan tajdid. Tajdid di sini bermakna pemurnian (purification) sekaligus pembaruan (reformation). Pemurnian mengandung arti Muhammadiyah ingin memurnikan pengamalan keberagamaan (aspek ibadah) ummat Islam yang telah bercampur baur dengan takhayul, bid'ah dan khurafat (TBKh). Sementara pembaruan berarti Muhammadiyah ingin ummat Islam dapat menyesuaikan diri dengan kehidupan modern (aspek muamalah). Dengan posisi sebagai gerakan tajdid, artinya, sejak awal didirikan Muhammadiyah merupakan bagian dan sekaligus mata rantai dari gerakan pembaruan Islam modern, terutama yang berkiblat pada gagasan tokoh pembaru Islam dari Mesir, Syeikh Muhammad Abduh (1849 - 1905). ${ }^{4}$

Bahwa Muhammadiyah merupakan bagian dan sekaligus mata rantai dari gerakan pembaruan Islam modern, hal ini dibenarkan oleh dua orang sejarawan dan sosiolog Belanda, Bernard Vlekke dan Wertheim. Kedua pakar tersebut mengkategorikan Muhammadiyah sebagai gerakan puritan yang fokus utamanya adalah melakukan "pemurnian atau pembersihan ajaran-ajaran Islam dari sinkretisme dan belenggu formalisme". ${ }^{5}$

Meskipun Muhammadiyah tidak dapat dilepaskan akarnya dari gerakan pembaruan Islam modern, khususnya pemikiran Abduh dari Mesir, namun menurut Ahmad Najib Burhani, Muhammadiyah dalam kepemimpinan pendirinya, Ahmad Dahlan menunjukkan karakter budaya Jawa yang sangat kental. Hal ini berarti bahwa Muhammadiyah sejak awal telah memiliki kearifan lokal (local genious) yang tinggi. Karakter budaya Jawa pada Muhammadiyah awal dikuatkan oleh fakta bahwa tujuh dari sembilan pemimpin awal Muhammadiyah adalah abdi dalem, bangsawan yang menjadi pegawai Keraton Yogyakarta. Sebagai abdi dalem, tentu saja mereka sangat menghayati dan dalam tataran tertentu mengaplikasikan budaya Jawa mereka. Pemimpin dan anggota awal Muhammadiyah adalah dari kalangan priyayi-santri (bangsawan keagamaan) dan priyayi-nonsantri (bangsawan yang merupakan jebolan

${ }^{3}$ Zakiyuddin Baidhawy dan Azaki Khoiruddin. 2017. Etika Muhammadiyah dan Spirit Peradaban. Yogyakarta: Suara Muhammadiyah, hlm. 1.

${ }^{4}$ Gagasan Abduh, menurut H.R. Gibb, dapat diringkas dalam empat aspek, yaitu: (1) pemurnian Islam dari berbagai pengaruh ajaran dan pengamalan yang kurang benar, (2) pembaruan pendidikan Islam yang terfokus pada pendidikan tinggi, (3) perumusan kembali ajaran Islam yang sejalan dengan perkembangan zaman modern, dan (4) pembelaan Islam terhadap pengaruh-pengaruh dari Eropa serta serangan-serangan Kristen. Periksa H.A.R. Gibb, Aliran-aliran Moderen dalam Islam, terjemahan Machnun Husein, (Jakarta: Citra Niaga Rajawali Pers, 1993), hlm. 58.

${ }^{5}$ Alwi Shihab, Islam Inklusif, (Bandung: Mizan, 1997), hlm. 304. 
pendidikan Barat), baru selanjutnya kalangan pedagang dan pengusaha. Semuanya dapat disebut sebagai representasi kelas menengah, dan bahkan mungkin kelas menengah atas, yang tinggal di wilayah perkotaan (urban). ${ }^{6}$

Dalam artikel ini, penulis akan mencoba menganalisis kelahiran Muhammadiyah dari perspektif hermeneutik, terutama mengacu pada pemikiran Hans Georg Gadamer dari Jerman. Setelah dibuka dengan pendahuluan, berturutturut akan dibahas mengenai perspektif hermeneutik, biografi singkat Ahmad Dahlan, pokok-pokok pikiran Ahmad Dahlan dan identitas Muhammadiyah, kelahiran Muhammadiyah dalam perspektif hermeneutik, dan artikel ini diakhiri dengan penutup.

\section{PERSPEKTIF HERMENEUTIK}

Kata hermeneutik secara etimologis berasal dari bahasa Yunani, yakni dari akar kata hermeneuein, yang artinya menafsirkan. Asal muasal kata ini terkait dengan tokoh yang bernama Hermes dalam mitologi Yunani. Tokoh bernama Hermes ini merupakan seorang utusan dari Dewa Jupiter dengan tugas menyampaikaan pesan Tuannya kepada manusia. Tugas menyampaikan pesan yang dilakoni Hermes dapat diartikan sebagai menerjemahkan perkataan Dewa Jupiter ke dalam bahasa yang dimengerti oleh manusia. Penerjemahan dapat dikatakan identik dengan penafsiran. Jadi, dari situ kemudian berkembang pengertian bahwa hermeneutika berkaitan dengan penafsiran atau interpretasi. ${ }^{7}$

Hermeneutika mencakup dua fokus perhatian yang berbeda namun saling berinteraksi, yakni: (1) peristiwa pemahaman teks, dan (2) persoalan yang lebih mengarah pada pemahaman dan interpretasi. Dalam hermeneutika, interpretasi merupakan aktivitas berpikir manusia yang sangat mendasar. Hermeneutika awalnya digunakan dalam penelitian di bidang teologi, filsafat dan sastra. Hal ini tampak dari definisi hermeneutika menurut Webster's Third News International Dictionary, bahwa "hermeneutika adalah studi tentang prinsip-prinsip metodologis interpretasi dan eksplanasi, khususnya studi tentang prinsip-prinsip umum interpretasi Bibel" .8

Ada banyak tokoh yang mengembangkan pendekatan hermeneutika, di antaranya adalah F.D.E. Schleiermarcher, Wilhelm Dilthey, Martin Heidegger, HansGeorg Gadamer, Jurgen Habermas, dan Paul Ricoeur. Penulis tidak menjelaskan pemikiran hermeneutika dari semua tokoh tersebut. Penulis hanya menampilkan pemikiran Hans-Georg Gadamer, yang dirujuk sebagai sumber dan alat analisis untuk memahami kelahiran Muhammadiyah.

${ }^{6}$ Lihat Ahmad Najib Burhani, Muhammadiyah Jawa, terjemahan Izza Rohman Nahrowi, (Jakarta: Al Wasat Publishing House, 2010), hlm. 85 - 94.

${ }^{7}$ Acep Iwan Saidi, “Hermeneutika, Sebuah Cara untuk Memahami Teks," dalam Jurnal Sosioteknologi Edisi 13 Tahun 7, April 2008, hlm. 376.

${ }^{8}$ Richard E. Palmer, Hermeneutika Teori Baru Mengenai Interpretasi. Terjemahan Musnur Hery dan Damanhuri Muhammad, Cetakan Kedua, (Yogyakarta: Pustaka Pelajar, 2005), hlm. 3,8 dan 9 . 
Hans-Georg Gadamer adalah seorang guru besar filsafat pada Universitas Heidelberg Jerman. Dia berasal dari lingkungan Marburg yang pada saat itu tengah mengalami disintegrasi, dan Gadamer berusaha mencari orientasi baru dalam suatu dunia yang kehilangan orientasi. Gadamer banyak dipengaruhi oleh pemikiran Martin Heidegger yang mengembangkan hermeneutika filsafati. Analisis Heidegger tentang eksistensi manusia, menurut Gadamer sebagaimana dikutip oleh Poespoprodjo, telah menunjukkan bahwa pemahaman bukan satu sikap seseorang sebagai subyek manusia, melainkan cara berada dari wujud manusia itu sendiri. Gadamer menggunakan istilah hermenutika untuk menunjukkan gerakan dasar dari eksistensi manusia yang terdiri atas keterbatasan dan historikalitas. Bahwa pemahaman meliputi keseluruhan dari pengalaman manusia tentang dunia, sehingga gerak pemahaman bersifat meliputi dan universal. ${ }^{9}$

Pemikiran hermeneutika Gadamer tergolong dalam hermeneutika dialektikospekulatif. Gadamer mendapatkan gambaran pengalaman dialektis dari Hegel, bahwa pengalaman mempunyai struktur pembalikan atau struktur kesadaran, dan struktur kesadaran merupakan bentuk dialektis gerakan. Menurut Hegel, pengalaman merupakan obyektivikasi diri mengenai kesadaran, sehingga pengalaman didekati dari suatu keadaan yang menguntungkan bagi pengetahuan yang mentransendensikannya. Gadamer menentang transendensi obyektivitas pengetahuan dari Hegel. Bahwa pengalaman memiliki penggabungan dialektis "tidak dalam pengetahuan tetapi dalam keterbukaan pengalaman, yang lahir dari ruang bebas pengalaman". ${ }^{10}$

Pemikiran Gadamer juga menekankan pentingnya tradisi. Bahwa keberadaan manusia lewat dan ada di dalam tradisi. Selanjutnya Gadamer menyebutkan bahwa situasi sebenarnya saat pemahaman terjadi adalah selalu berupa pemahaman melalui bahasa dan tradisi. Tradisi bukan suatu substansi dan bukan pula material, melainkan suatu proses yang menyatu dengan keberadaan atau eksistensi manusia. Bahwa manusia atau diri kita selalu berdiri dalam tradisi. Keterlibatan atau partisipasi pada warisan budaya yang meliputi sesuatu yang akan dipahami merupakan prakondisi untuk tercapainya pemahaman. ${ }^{11}$

Gadamer menyatakan bahwa pemahaman bersifat historikal ini sejalan dengan tesis Heidegger bahwa ada secara radikal bersifat historikal. Artinya bahwa pemahaman, bahkan juga manusia itu sendiri dikuasai oleh sejarah. Lebih jauh, menurut Gadamer dalam kutipannya Poespoprodjo:

“agaknya tidak dapat diragukan lagi bahwa cakrawala besar masa-lalu tempat kebudayaan dan masa-kini kita hidup, memengaruhi kita dalam setiap hal yang kita maui, kita harapkan atau kita takutkan dan khawatirkan di masa-depan". ${ }^{12}$

${ }^{9}$ Lihat dalam W. Poespoprodjo L., Hermeneutika, (Bandung: Pustaka Setia, 2004), hlm. $92-93$.

${ }^{10}$ Richard E. Palmer, op. cit., hlm. 232.

${ }^{11}$ W. Poespoprodjo, op.cit, hlm. 97.

${ }^{12}$ Ibid., hlm. 94. 
Dengan kata lain, bagi Gadamer, sejarah dan masa lalu merupakan suatu struktur dengan pemahaman, pengetahuan, dan pikiran kita. Bahwa gerak historikal menjadi inti pemahaman, pengetahuan, dan pikiran kita. Disadari ataupun tidak, pemahaman merupakan hasil interaksi antara masa lalu dengan masa kini. Dalam pandangan Gadamer, kunci untuk mendapatkan pemahaman adalah dengan keterlibatan atau partisipasi dan keterbukaan, bukan dengan manipulasi dan pengendalian. ${ }^{13}$

Lebih jauh menurut Gadamer, dengan menyatakan bahwa pemahaman adalah historikal, maka masa lalu berpengaruh secara aktif pada masa kini. Masa kini dapat dilihat dan dipahami dengan baik hanya melalui pencermatan terhadap konsepkonsep yang diwarisi dari masa lalu. Gadamer memandang masa lalu seperti arus yang memungkinkan kita bergerak dan mengambil bagian dalam setiap aktivitas pemahaman. Dari sinilah muncul "kesadaran menyejarah" (wirkungsgeschichtliche bewusstsein), yakni kesadaran pada diri manusia atau diri kita bahwa sejarah senantiasa bergiat untuk mencipta bagi masa depan. ${ }^{14}$

Wirkungsgeschichtliche bewusstsein yang dapat diartikan sebagai kesadaran menyejarah, kesadaran di mana sejarah berlaku, kesadaran operatif historis, atau kesadaran historis otentik. Dengan istilah yang terakhir, kesadaran historis otentik dimaksudkan sebagai suatu kesadaran spekulatif dan dialektis dalam struktur pengalaman. Ini jelas bukan kesadaran historis Hegelian yang menempatkan kesadaran dalam atmosfir refleksifitas dan menjadikannya sebagai mediasi sejarah dan masa kekinian. ${ }^{15}$

Pandangan hermeneutik Gadamer yang digunakan untuk menganalisis kelahiran Muhammadiyah adalah pemahaman sebagai hasil interaksi antara masa lalu dengan masa kini, yang didapatkan melalui partisipasi dan keterbukaan. Pemahaman yang dinamis inilah yang disebut sebagai "kesadaran menyejarah" sehingga menghasilkan kreasi untuk masa dean.

\section{BIOGRAFI SINGKAT AHMAD DAHLAN}

Ahmad Dahlan lahir dengan nama Muhammad Darwis pada tahun $1868 \mathrm{M}$ bertepatan dengan $1285 \mathrm{H}$, di Kauman, Yogyakarta. ${ }^{16}$ Ayahnya bernama Abu Bakar

${ }^{13}$ Ibid., hlm. 95.

${ }^{14}$ Ibid., hlm. 98 - 99.

${ }^{15}$ Richard E. Palmer, op. cit., hlm. 226.

${ }_{16}$ Sebenarnya mengenai angka tahun kelahiran Ahmad Dahlan belum dapat diketahui dengan pasti, namun berkisar antara tahun 1868 dan 1869. Periksa dalam M. Yusron Asrofie, Kyai Haji Ahmad Dahlan Pemikiran dan Kepemimpinannya, (Yogyakarta: MPK-SDI PP Muhammadiyah, 2005), hlm. 12. Jika M. Yusron Asrofie lebih condong menyebut tahun kelahiran Ahmad Dahlan adalah 1868, maka sumber yang lain, yakni Syuja' menyebut 1869 sebagai tahun kelahiran pendiri Muhammadiyah tersebut. Lihat dalam K.H. Syuja', Islam Berkemajuan Kisah Perjuangan K.H. Ahmad Dahlan dan Muhammadiyah Masa Awal, (Yogyakarta: Al-Wasat, 2009), hlm. 1. Mestinya tahun kelahiran Ahmad Dahlan yang lebih dapat dipercaya adalah 1869 karena dikemukakan oleh Syuja' sebagai murid pendiri Muhammadiyah. 
bin Muhammad Sulaiman, seorang ulama dan khatib terkenal di Masjid Besar Kesultanan Yogyakarta. Sedangkan ibunya, Siti Aminah, adalah putri Ibrahim bin Hasan, seorang pejabat Kapengulon (Penghulu Besar) Kesultanan di Yogyakarta.

Silsilah Ahmad Dahlan apabila mau ditelusuri akan sampai ke Maulana Malik Ibrahim, salah satu wali yang berpengaruh di antara Wali Songo. Ayah Ahmad Dahlan, yakni Abu Bakar, adalah putra dari Muhammad Sulaiman. Selanjutnya berturut-turut dapat digambarkan silsilahnya sebagai berikut:

“Kiai Abu Bakar adalah putra Kiai Haji Sulaeman dari ayah Kiai Murtadla yang ayahnya, Ki Demang Juru Kapisan, adalah putra Maulana Sulaeman yang dikenal dengan Kiai Ageng Gribig anak dari Maulana Fadlullah. Dari Maulana Fadlullah inilah garis keturunan Kiai Dahlan mulai bersambung darah dengan Maulana Malik Ibrahim. Maulana Malik Ibrahim dikenal sebagai penyebar agama Islam di daerah Jawa Timur tepatnya di Gresik sekitar abad ke-15. Salah seorang putra Maulana Malik Ibrahim bernama Maulana Ishaq yang memiliki putra bernama Maulana 'Ainul Yaqin". ${ }^{17}$

Pendidikan agama pertama kali dia terima langsung dari orangtuanya. Saat itu kebiasaan anak-anak kiai Kauman adalah belajar ilmu Fiqh, Al-qur'an, tata bahasa Arab, seperti nahwu dan sharaf, hadis dan ilmu-ilmu lainnya. Mereka pun belajar pencak silat sebagai bela diri. Pada saat itu kondisi masyarakat sekitar Kauman, jika belajar di sekolah milik penjajah maka akan dicap sebagai kafir. Pusat kegiatan mereka dalam menimba ilmu adalah masjid atau surau. Beberapa guru Ahmad Dahlan adalah K.H. Muhammad Saleh, K.H. Muchsin, K.H. Abdul Hamid, K.H. Muhammad Nur, K.R.H. Dahlan (ilmu falaq), K. Mahfud dan Syeikh Khayyat (hadits), Syeikh Amien dan Sayyid Bakri Satok (qira'ah), Syeikh Hasan (ilmu bisa ular), juga Syeikh M. Jamil Jambek. ${ }^{18}$

Dengan demikian, Ahmad Dahlan tidak pernah mengenyam pendidikan formal, yakni masuk pada sekolah tertentu. Akan tetapi, ternyata dia menguasai beraneka ragam ilmu yang terutama diperoleh dengan belajar sendiri (otodidak), selain dari berguru kepada ulama atau seorang ahli, juga dengan membaca buku atau kitab. Menurut A. Munir Mulkhan, bberapa ilmu yang dikuasai oleh Ahmad Dahlan dengan sangat baik adalah : (1) Nahu (tata bahasa Arab), (2) Fiqih, (3) Falaq (ilmu

Sebaliknya penyebutan tahun 1868 oleh M. Yusron Asrofie merujuk sumbernya pada Solichin Salam.

17 Lihat A. Munir Mulkhan, Pesan dan Kisah Kiai Ahmad Dahlan Dalam Hikmah Muhammadiyah, (Yogyakarta: Suara Muhammadiyah, 2010), hlm. 5 - 6. Yang agak berbeda dikemukakan oleh M. Yusron Asrofie, bahwa Kiyai Murtadla adalah putra Kiyai Ilyas, putra dari Demang Jurang Juru Kapindo, putra dari Demang Jurang Juru Kapisan, putra dari Maulana Sulaiman (Ki Ageng Gribig), putra dari Maulana Fadlullah, putra dari Maulana 'Ainul Yakin, putra dari Maulana Ishak, putra dari Maulana Malik Ibrahim. Periksa dalam M. Yusron Asrofie, op. cit., hlm. 32 - 33.

${ }^{18}$ M. Yusron Asrofie, ibid., hlm. $33-34$. 
perbintangan), (4) Hadits, (5) Qiraatul Qur'an, (6) Pengobatan dan racun, (7) Filsafat, dan (8) Tasawwuf. ${ }^{19}$

Dalam tahun 1889, Ahmad Dahlan menikah dengan Siti Walidah binti Haji Fadhil seorang pahlawan nasional dan pendiri 'Aisyiyah yang kelak akan lebih dikenal dengan sebutan Nyai Ahmad Dahlan, yang ternyata masih saudara dari garis ibunya (saudara sepupu). Dari perkawinannya dengan Siti Walidah, Ahmad Dahlan mendapatkan enam orang anak, yaitu: Djohanah, Siradj Dahlan, Siti Busyro, Irfan Dahlan, Siti Aisyah, dan Siti Zaharah. Di samping itu, Ahmad Dahlan pernah pula menikahi beberapa orang perempuan. Di antaranya: Nyai Abdullah (janda $\mathrm{H}$. Abdullah] dan mempunyai anak R. Duri. Ahmad Dahlan juga menikahi Nyai Rum (punya anak laki-laki tapi meninggal saat masih bayi), lalu menikahi Nyai Aisyah dan mendapat seorang anak putri (Dandanah], dan terakhir menikahi Nyai Solihah. Tetapi hanya Nyai Dahlan yang mendampingi K.H. Ahmad Dahlan sampai beliau wafat. ${ }^{20}$

Pada 1890, beliau menunaikan ibadah haji ke Mekkah selama sekitar delapan (8) bulan. Menurut Syuja', Ahmad Dahlan sampai di Mekah pada 25 Rajab, dan segera pulang setelah ibadah hajinya selesai dalam bulan Dzulhijah. ${ }^{21}$ Artinya, di Tanah Arabia, Ahmad Dahlan tinggal (mukim) selama kira-kira lima (5) bulan. Jika perjalanan dengan kapal api dari Indonesia menuju Jeddah diperlukan waktu selama satu setengah $(1,5)$ bulan, maka pulang pergi dari Arabia sampai Indonesia dibutuhkan waktu tiga (3) bulan. Sehingga, wajar kalau perjalanan haji Ahmad Dahlan berlangsung selama delapan (8) bulan. Beliau mendapat gelar atau ijazah nama Ahmad Dahlan dari guru yang ditemuinya di Mekah, bernama Sayyid Bakri Syatha, seorang alim pengikut Imam Syafii. ${ }^{22}$

Ada dugaan kuat bahwa pada waktu menunaikan ibadah haji yang pertama itu, Ahmad Dahlan sudah mengenal gagasan pembaruan Islam, minimal ajaran dari Ibnu Taymiyah dan Muhammad ibnu Abdul Wahhab. Terbukti, sepulangnya dari Mekkah, beliau memang membantu ayahnya mengajar agama di Kampung Kauman dan menggantikan jabatan ayahnya sebagai Khatib di Masjid Kesultanan sehingga dipanggil Ahmad Dahlan, namun episode terpenting dari kehidupan beliau adalah upaya meluruskan arah kiblat pada $1898 .{ }^{23}$

Pada ibadah haji yang kedua (1903-1904), Ahmad Dahlan yang membawa serta putranya yang masih kecil, Muhammad Siraj, cukup lama bermukim di Mekah, yakni selama delapan belas $(18)$ bulan atau satu setengah $(1,5)$ tahun. Selain belajar pada alim ulama yang berada di Mekah, seperti Syeikh Shalih Bafadlol, Syeikh Sa'id Jamani, Syeikh Babusyel dan Syaikh Muhammad Khatib yang berasal dari Minangkabau, Ahmad Dahlan ternyata juga menimba ilmu dari ulama Indonesia yang tengah beribadah haji atau mukim di Mekah, seperti: Kyai Makhfudz dari Termas, Kyai Muhtaram dari Banyumas, Kyai Nawawi dari Banten, Kyai Mas Abdullah dari

\footnotetext{
${ }^{19}$ A. Munir Mulkhan, op. cit., hlm. 7.

${ }^{20}$ Lihat dalam M. Yusron Asrofie, op.cit., hlm. 34.

${ }^{21}$ Periksa K.H. Syuja', op. cit., hlm. 10 - 13.

22 Ibid.

${ }^{23}$ Baca mengenai ihwal perjuangan K.H. Ahmad Dahlan meluruskan arah kiblat dalam
} K.H. Syuja', ibid, hlm. 31 - 38; bdk. M. Yusron Asyrofie, op. cit., hlm. 54 - 59. 
Surabaya, dan Kyai Faqih Maskumambang dari Gresik. ${ }^{24}$ Terdapat dugaan kuat bahwa Ahmad Dahlan telah mendalami gagasan-gagasan pembaruan Islam, baik dari Ibnu Taymiyah, Muhammad ibnu Abdul Wahhab hingga Syeikh Muhammad Abduh.

Pasca menunaikan ibadah haji yang kedua, tampaknya Ahmad Dahlan telah memiliki komitmen yang kuat untuk melakukan pembaruan Islam di Indonesia, khususnya dengan cara memurnikan amal peribadatan dari kebiasaan dan tradisi yang tergolong bid'ah dan khurafat. Namun, menurut Deliar Noer, komitmen Ahmad Dahlan untuk mengadakan pembaruan Islam adalah setelah beliau bertemu dan bercakap-cakap dengan Syaikh Akhmad Syurkati, yang belakangan menjadi pemimpin utama organisasi Al-Irsyad, di sebuah gerbong kereta api. ${ }^{25}$

Pada 1912, tepatnya tanggal 18 Nopember 1912, Ahmad Dahlan pun mendirikan organisasi Muhammadiyah untuk melaksanakan cita-cita pembaruan Islam di bumi Nusantara. Ahmad Dahlan ingin mengadakan suatu pembaruan dalam cara berpikir dan beramal menurut tuntunan agama Islam. Beliau ingin mengajak umat Islam Indonesia untuk kembali hidup menurut tuntunan al-Qur'an dan alHadits. Sejak awal Ahmad Dahlan menetapkan bahwa Muhammadiyah bukan organisasi politik tetapi bersifat sosial dan bergerak di bidang pendidikan.

Sampai akhir hayatnya (beliau wafat tahun 1923) Ahmad Dahlan menjadi ketua Pusat / HB Muhammadiyah. Dengan bendera Muhammadiyah yang dikibarkannya sejak 1912 telah melakukan banyak pekerjaan besar bagi kemajuan bangsa dan masa depan umat Islam. Atas jasa-jasa Ahmad Dahlan dalam membangkitkan kesadaran bangsa ini melalui pembaruan Islam dan pendidikan, maka Pemerintah Republik Indonesia menetapkannya sebagai Pahlawan Nasional dengan surat Keputusan Presiden no. 657 tahun $1961 .{ }^{26}$

\section{Pokok-pokok Pikiran K.H. Ahmad Dahlan dan Identitas Muhammadiyah}

Sebenarnya Ahmad Dahlan merupakan tipe ulama yang tergolong sebagai manusia amal (man of action), yang lebih menekankan perbuatan dan karya nyata ketimbang banyak berkata-kata. Beliau tidak banyak meninggalkan karya-karya tertulis. Hal itu bukan disebabkan karena tidak adanya sarana untuk mengungkapkan buah pikiran dalam bentuk tulisan, melainkan karena bagi Ahmad Dahlan ajaran agama tidak sekedar doktrin namun harus diwujudkan dalam praksis sosial. Salah satu contohnya adalah ajaran atau teologi Al-Ma'un yang diambil dari Al Quran Surah Al-Ma'un, diajarkan oleh Ahmad Dahlan kepada para santrinya dengan cara praktik langsung memberikan empati, perawatan, dan pelayanan sosial khususnya kepada

\footnotetext{
${ }^{24}$ K.H. Syuja', op. cit., $52-53$.

${ }^{25}$ Deliar Noer, Gerakan Moderen Islam di Indonesia 1900-1942, (Jakarta: LP3ES, 1990), hlm.
} 87.

${ }^{26}$ Lihat Eddy Soetrisno dan Elizabeth Tara (editor), Buku Pintar 100 Tokoh Pahlawan Nasional dan Sejarah Perjuangannya, (Jakarta: Ladang Pustaka dan Intimedia, 2001), hlm. 49 50. 
orang jompo, fakir-miskin dan anak yatim. Intinya adalah penafsiran Al Quran yang dapat lebih membumi dalam konteks kehidupan nyata. ${ }^{27}$

Dalam pandangan Ahmad Syafii Maarif, Ahmad Dahlan selaku pendiri Muhammadiyah dikenal sebagai salah seorang ulama yang sangat peka dan bahkan mungkin yang paling gelisah pada zamannya karena menyadari sepenuhnya bahwa kondisi umat Islam Indonesia ketika itu sedang terpuruk tanpa harkat dan martabat. Fenomena yang merupakan realitas sosial umat Islam pada saat itu adalah kemiskinan, keterbelakangan dan kebodohan dalam beragama. Tantangan tersebut dijawab oleh Ahmad Dahlan dengan perbuatan kongkrit, yakni umat harus dicerdaskan dan dicerahkan. Artinya, penyakit-penyakit sosial tidak dapat diobati tanpa aksi nyata. Tidak heran bila Ahmad Dahlan merupakan sosok man of action yang sangat tanggap terhadap tantangan zamannya. Filosofi sosial yang diajarkan oleh Ahmad Dahlan, yaitu berbuat dan beramal sebagai perintah iman, selanjutnya berkembang menjadi trade mark-nya Muhammadiyah hingga sekarang. Muhammadiyah tidak akan pernah melupakan misi sosial, pendidikan dan kemanusiaan yang telah melekat menjadi jati diri gerakan Muhammadiyah. ${ }^{28}$

Penulis sendiri memandang Muhammadiyah sebagai bagian dan mata rantai dari gerakan wong cilik, yang telah diletakkan posisinya oleh Ahmad Dahlan sendiri sebagai pendiri Muhammadiyah. Sebagai gerakan wong cilik, artinya Muhammadiyah sangat peduli dan memperhatikan kelompok masyarakat bawah, rakyat jelata,

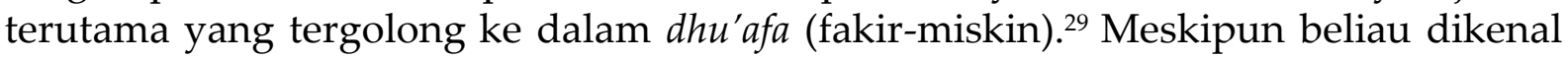
sebagai seorang pedagang batik yang cukup kaya, namun beliau sangat dermawan dan senantiasa bersedia menyantuni kelompok umat yang tidak mampu alias wong cilik. Salah satu contoh kedermawanan beliau tampak dalam peristiwa berikut.

"Suatu ketika ada seorang fakir menghampiri K.H. Ahmad Dahlan dan mengatakan tidak memiliki pakaian yang bersih untuk shalat. Tanpa berpikir panjang, K.H. Ahmad Dahlan mengajak orang fakir tersebut ke rumahnya dan langsung dibawa masuk ke kamarnya. Di dalam kamar, beliau mempersilahkan si fakir untuk memilih pakaian yang disenanginya dan diberikannya secara langsung. Belakangan diketahui si fakir tersebut adalah Raden Aspari, pendiri Muhammadiyah di daerah Sumber Pucung. ${ }^{30}$

${ }^{27}$ Baca pada pengantar penerbit untuk buku karya K.R.H. Hajid, Pelajaran K.H. A. Dahlan 7 Falsafah Ajaran dan 17 Kelompok Ayat Al-Quran, (Malang: UMM Press, 2005), hlm. v vi.

${ }^{28}$ Ahmad Syafii Maarif, "Revitalisasi Ideologi Gerakan Muhammadiyah," dalam Edy Suandi Hamid, M. Dasron Hamid dan Sjafri Sairin (penyunting), 2000, Rekonstruksi Gerakan Muhammadiyah pada Era Multiperadaban (Yogyakarta: UII Press), hlm. 109.

29 Lihat dalam buku penulis, Suwarno, Relasi Muhammaiyah, Islam dan Negara (Kontribusi Muhammadiyah dalam Perspektif Sejarah), (Yogyakarta: Pustaka Pelajar, 2010), hlm. $29-30$.

30 Hery Sucipto dan Nadjamuddin Ramly, Tajdid Muhammadiyah dari Ahmad Dahlan hingga A. Syafii Maarif (Jakarta: Grafindo Khazanah Ilmu, 2005), hlm. 32. 
Beberapa pokok pikiran Ahmad Dahlan dapat dijelaskan sebagai berikut. Menurut pendapat Ahmad Dahlan, kemunduran umat Islam lebih disebabkan karena sebagian besar umat Islam terlalu jauh meninggalkan ajaran agama Islam. Umat Islam tidak lagi memegang teguh tuntunan Al Quran dan Sunnah Nabi. Inilah yang menyebabkan merebak dan merajalelanya syirik, bid'ah dan khurafat di kalangan umat Islam. Agama Islam tidak lagi memancarkan sinar kemurniannya lagi. Akibatnya, umat Islam pun tidak lagi menjadi suatu golongan yang terhormat di masyarakat. ${ }^{31}$

Selain itu, dalam pandangan Ahmad Dahlan, kemunduran umat Islam juga disebabkan karena kemerosotan akhlak umat islam sendiri, yang dapat diibaratkan sebagai "penuh ketakutan seperti kambing dan tidak lagi memiliki keberanian seperti harimau". Mencermati kemerosotan akhlak umat Islam itu, Ahmad Dahlan menyatakan:

"Karena itu aku terus memperbanyak amal dan berjuang bersama anakanakku sekalian untuk menegakkan akhlak dan moral serta berbagai persoalan Islam yang sudah bengkok memang merupakan tugas berat dan sulit". 32

Menurut Ahmad Dahlan, sebab-sebab mengapa umat manusia, khususnya umat Islam, tidak mau menerima kebenaran adalah: (1) bodoh, belum mengetahui atau mengerti ajaran Islam yang benar, (2) belum datangnya ajaran Islam yang benar, (3) tidak cocok dengan orang yang membawa kebenaran, apalagi jika orang itu dianggap sebagai musuh, (4) mereka telah mempunyai kebiasaan-kebiasaan agama yang telah dicintainya terlebih dahulu, (5) mereka takut berpisah dengan keluarganya, kawan-kawannya, (6) takut kehilangan apa yang menjadi kesenangannya, dan (7) tidak berani menjalankan kebenaran karena takut sakit dan mati. $^{33}$

Penulis juga telah meringkas 7 falsafah ajaran Ahmad Dahlan, sebagaimana yang disebarluaskan oleh murid beliau (Hadjid), yang menurut penulis masih relevan dengan kondisi umat Islam sekarang. Ke-7 falsafah ajaran Ahmad Dahlan adalah:

1. "Kita, manusia ini, hidup di dunia hanya sekali, untuk bertaruh: sesudah mati, akan mendapat kebahagiaankah atau kesengsaraankah?"

2. "Kebanyakan manusia berwatak angkuh dan takabbur, mereka mengambil keputusan sendiri-sendiri."

3. "Manusia itu kalau mengerjakan pekerjaan apapun berulang-ulang hingga menjadi biasa. Kalau sudah menjadi kebiasaan yang disenangi maka sulit sekali untuk diubah (menjadi semacam i'tiqad / keyakinan, dan taqlid pada keyakinan itu)."

4. "Manusia harus mempergunakan akal pikirannya untuk memahami agama dan mencari kebenaran yang sejati."

${ }^{31}$ Baca Junus Salam, K.H. Ahmad Dahlan Amal dan Perjuangannya, (Jakarta: Al Wasat, 2009), hlm. 100.

32 Lihat dalam A. Munir Mulkhan, op. cit., hlm. 203 - 204.

${ }^{33}$ Periksa dalam M. Yusron Asrofie, op. cit., hlm. 64. 
5. "Kebanyakan manusia hidup asal hidup, hidup sebagai makhluk yang tak berakal, dan tidak menetapi kebenaran."

6. "Kebanyakan pemimpin tidak mau berkorban, malahan suka memperalat dan mempermainkan manusia yang lemah dan bodoh."

7. "Belajar, khususnya belajar agama, harus mempelajari teori dan mempraktikkannya, agar ilmu yang dimilikinya bermanfaat." 34

Alasan mengapa persyarikatan yang beliau dirikan menggunakan nama Muhammadiyah adalah agar seluruh umat berjiwa Islam akan selalu tetap mencintai junjungan Nabi Muhammad saw dengan mengamalkan segala tuntunan dan perintahnya. Selanjutnya kepada umat Islam, khususnya warga Muhammadiyah, beliau berpesan -yang menurut A. Munir Mulkhan disebut sebagai khittah Ahmad Dahlan- untuk: (1) tidak menduakan Muhammadiyah dengan organisasi lain; (2) tidak dendam, tidak marah dan tidak sakit hati jika dicela dan dikritik; (3) juga tidak sombong dan tidak berbesar hati jika menerima pujian; (4) tidak jubria (ujub, kikir dan riya), (5) selalu bersedia mengorbankan harta benda, pikiran dan tenaga dengan hati yang ikhlas dan murni; serta (6) bersunguh hati terhadap pendirian. ${ }^{35}$

\section{KELAHIRAN MUHAMMADIYAH DALAM PERSPEKTIF}

\section{HERMENEUTIK}

Muhammadiyah didirikan oleh Ahmad Dahlan pada 18 November 1912 bertepatan tanggal 8 Dzulhijah $1330 \mathrm{H}$. Tokoh ini dikenal sebagai ulama yang 'alim, saleh, moderat, tolerans, dan sangat peduli (concern) dengan keadaan umat Islam pada saat itu yang mengalami kondisi keterbelakangan, kemiskinan dan kebodohan.

Selama ini yang dipahami dari latar belakang mengapa Ahmad Dahlan mendirikan Muhammadiyah adalah adanya 2 faktor: subyektif dan obyektif. Faktor subyektif berangkat dari pergulatan pemikiran yang dialami K.H. Ahmad Dahlan dengan gagasan-gagasan pembaruan Islam (baik yang pra-modern maupun yang modern), dan keprihatinan beliau akan kondisi obyektif kaum Muslim seperti kehidupan keagamaan yang tidak murni, Kristenisasi yang dilancarkan oleh missi dan zending, serta penjajahan Belanda yang dampaknya sangat berat dirasakan oleh rakyat. Faktor obyektif berkenaan dengan kondisi internal dan eksternal kaum Muslim Indonesia. Kondisi internal kaum Muslim, di sini mengutip Hamka (19081981) dan Kuntowijoyo (1943-2005).

Hamka, sebagaimana dikutip oleh Ahmad Syafii Ma'arif, melihat tiga (3) faktor pendorong lahirnya Muhammadiyah, yaitu: (1) keterbelakangan dan kebodohan umat Islam Indonesia pada hampir semua bidang kehidupan, (2) kemiskinan yang parah diderita oleh umat Islam padahal hidup di negeri yang kaya raya, dan (3) kondisi pendidikan Islam yang sudah sangat kuno seperti terlihat pada pesantren. ${ }^{36}$

${ }_{34}$ KRH. Hadjid, 2005, op. cit., hlm. 7-29.

35 A. Munir Mulkhan, op. cit., hlm. 204 dan 206.

${ }^{36}$ Lihat dalam Ahmad Syafii Ma'arif, Islam dan Masalah Kenegaraan Studi tentang

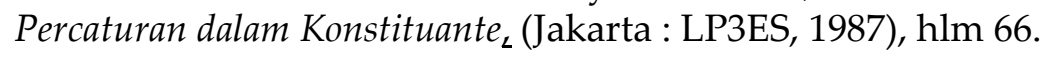


Kuntowijoyo yang mencermati dua lingkaran kultur umat Islam Indonesia menjelang kelahiran Muhammadiyah menyimpulkan bahwa ada dua kultur umat Islam yang mendorong Ahmad Dahlan untuk memurnikan dan memperbaruinya. Pertama, kultur Islam-sinkretis dengan budaya Jawa yang menghasilkan produk budaya Takhayul. Kedua, kultur Islam-tradisional yang menghasilkan produk budaya Bid'ah dan Khurafat. Tiga hal inilah (Takhayul, Bid'ah dan Khurafat / TBKh) yang ingin diberantas oleh Ahmad Dahlan dan Muhammadiyah. ${ }^{37}$

Kondisi eksternal ialah kolonialisme Belanda di Indonesia serta Kristenisasi yang ditimbulkannya, menurut Alwi Shihab dapat dipandang sebagai salah satu alasan pokok didirikannya Muhammadiyah oleh Ahmad Dahlan. Dalam pandangan Alwi Shihab, terdapat 4 masalah yang menjadi kepedulian utama Ahmad Dahlan, yang dipandangnya sebagai sumber kemunduran umat Islam di Indonesia, dan belakangan diupayakan solusinya melalui Muhammadiyah. Pertama, kehidupan agama umat Islam yang tidak murni. Kedua, pendidikan keagamaan di kalangan umat Islam yang tidak efisien. Ketiga, kegiatan para misionaris Kristen dalam "memurtadkan" umat Islam. Keempat, sikap masa bodoh dan bahkan antiagama di kalangan sebagian besar kaum intelektual Indonesia saat itu. ${ }^{38}$

Persoalannya sekarang adalah bagaimana kelahiran Muhammadiyah jika dianalisis dengan pendekatan hermeneutika, khususnya yang dikemukakan oleh Hans-Georg Gadamer? Ketika Gadamer memandang pemahaman sebagai hasil interaksi antara masa lalu dengan masa kini yang didapatkan melalui partisipasi dan keterbukaan, maka dapat dikatakan bahwa Ahmad Dahlan benar-benar telah memahami kondisi nyata umat Islam di lingkungan sekitarnya, baik secara internal maupun eksternal, sebagai hasil pergulatan antara masa lalu dengan masa kini. Pemahaman tersebut berangkat dari partisipasi yang dilakukan Ahmad Dahlan, tidak hanya ketika berada di tanah air, tetapi juga pada waktu beliau menunaikan ibadah haji di Mekah bertemu dengan banyak ulama dan keterbukaan saat menyelami gagasan-gagasan pembaruan Islam sejak dari ide-idenya Ibnu Taymiyah, Muhammad ibnu Abdul Wahhab, hingga gagasan-gagasannya Muhammad Abduh.

Pemahaman yang didapatkan Ahmad Dahlan melalui partisipasi dan keterbukaan telah membuat Ahmad Dahlan memiliki "kesadaran menyejarah" sehingga mampu menampilkan kreasi-kreasi baru untuk umat Islam ke depan yang lebih baik. Kenyataan ini dapat dianalogkan dengan merujuk pandangan Kuntowijoyo bahwa didirikannya Muhammadiyah oleh Ahmad Dahlan, dapat dianalisis sebagai lahirnya sebuah kesadaran teosentrik, yakni kesadaran baru terhadap nilai-nilai keagamaan (Islam) yang muncul dari dalam. Lebih jauh menurut Kuntowijoyo, Ahmad Dahlan telah mewariskan dua daya hidup yang kemudian menjadi pegangan para aktivis Muhammadiyah, yaitu teosentrisme dan aktivisme sosial. Dengan teosentrisme, segala sesuatu harus dikembalikan kepada Al Quran dan As Sunnah. Hal ini berarti, yang tidak bertentangan dengan keduanya boleh diambil

${ }^{37}$ Periksa dalam Koentowidjojo, "Muhammadiyah dalam Perspektif Sejarah", dalam M. Amien Rais, dkk. (ed.), Pendidikan Muhammadiyah dan Perubahan Sosial_(Yogyakarta : PLP2M, 1985), hlm. 35 - 39.

38 Baca dalam Alwi Shihab, Membendung Arus Respons Gerakan Muhammadiyah terhadap Penetrasi Kristen di Indonesia, (Bandung: Mizan, 1998), hlm. 111. 
sekalipun berkebalikan dengan tradisi. Misalnya, Ahmad Dahlan meniru sistem sekolah, kurikulum umum, rumah-rumah yatim, pendidikan wanita, rumah sakit, dan kepanduan yang berasal dari Barat Kristen untuk dijadikan sebagai amal usaha Muhammadiyah (AUM). Sementara dengan aktivisme sosial, Ahmad Dahlan mendirikan berbagai perhimpunan kesukarelaan (voluntary association), mulai dari organisasi Muhammadiyah, sekolah-sekolah Muhammadiyah, penerbitan brosurbrosur dan majalah-majalah untuk keperluan dakwah, dan lain-lain, yang bertentangan dengan kebiasaan cara beragama orang pada waktu itu. ${ }^{39}$

Gadamer juga menyatakan bahwa pemahaman yang berpijak pada pengalaman mempunyai penggabungan dialektis yang tidak terdapat dalam pengetahuan, namun berasal dari dalam keterbukaan pengalaman yang lahir dari ruang bebas pengalaman. Hal ini berarti sangat ditentukan oleh pribadi yang memiliki keterbukaan. Ahmad Dahlan merupakan tipe orang atau pemimpin yang mempunyai keterbukaan dalam menerima gagasan-gagasan pembaruan Islam dari para ulama Timur Tengah sebagaimana telah disebutkan di atas. Ahmad Dahlan juga memiliki keterbukaan untuk berkomunikasi dengan berbagai kalangan. Terbukti, merujuk pandangan A. Munir Mulkhan, Ahmad Dahlan selaku Ketua Muhammadiyah mempunyai hubungan pergaulan yang sangat luas, sehingga donatur Muhammadiyah terdiri dari berbagai kalangan di antaranya dari para politisi dan para birokrat, seperti pegawai kereta api dan irigasi. ${ }^{40}$ Bahkan, Ahmad Dahlan mempunyai hubungan yang cukup baik dengan para pastur Katholik, sebagian besar di antaranya terlibat dalam diskusi dan perdebatan teologis yang hangat dan panas, antara lain : Romo Van Lith, Van Driesse, Domine Bakker, Dr. Zwemmer, dan Dr. Lamberton. ${ }^{41}$

Dalam pernyataannya yang lain, Gadamer mengemukakan pentingnya tradisi. Keberadaan manusia melalui dan berada dalam tradisi. Bahwa pemahaman akan situasi yang sebenarnya selalu berupa pemahaman lewat bahasa dan tradisi. Bahwa keterlibatan pada tradisi sebagai warisan budaya merupakan prasyarat tercapainya pemahaman. Ahmad Dahlan yang memiliki keprihatinan sangat besar terhadap kondisi umat Islam tentu saja sangat memahami tradisi umat Islam sebagaimana sinyalemen Kuntowijoyo mengenai dua kultur umat Islam, kultur Islam-sinkretis yang menghasilkan produk budaya takhayul dan kultur Islam-tradisional yang menghasilkan produk budaya bid'ah dan khurafat.

Akan tetapi, Ahmad Dahlan bukanlah tipe orang yang larut dalam tradisi. Justru tradisi yang dinilai bertentangan dengan pemahaman beliau atas Islam yang murni itu harus diluruskan dan dibenarkan. Menurut kesaksian Syuja', salah seorang murid Ahmad Dahlan, menuturkan bahwa Ahmad Dahlan memiliki sifat berani untuk mengubah adat-istiadat dan tradisi yang bertentangan dengan agama, meskipun tradisi itu sudah turun menurun, dengan cara dan bahasa yang bijaksana.

${ }^{39}$ Periksa Kuntowijoyo, "Pengantar," dalam Alwi Shihab, Membendung Arus Respons Gerakan Muhammadiyah terhadap Penetrasi Misi Kristen di Indonesia, (Bandung: Mizan, 1998), hlm. xv - xviii.

${ }^{40}$ Lihat dalam A. Munir Mulkhan, op. cit., hlm. 18 - 19.

${ }^{41}$ Periksa dalam M. Yusron Asrofie, op. cit., hlm. 103 - 107. 
Pribadi Ahmad Dahlan kuat dan teguh pada pendirian yang didasarkan pada keyakinan iman, serta berani bertanggung jawab atas semua perbuatannya yang benar bagi agama. Namun itu semua didasari oleh sifatnya yang memang sejak kecil beliau bertabiat halus dan lemah lembut, serta sabar dan suka mengalah. ${ }^{42}$

Sifat dan tabiat terbuka seperti itulah yang mendorong keberhasilan atau kesuksesan Ahmad Dahlan dalam mendirikan, menumbuhkan, dan mengembangkan Muhammadiyah. Menurut Abdul Mu'ti, ketika memberikan pengantar untuk buku karangan Kyai Syuja' (2009), "Islam Berkemajuan Kisah Perjuangan Ahmad Dahlan dan Muhammadiyah Masa Awal", menyebut adanya lima fondasi Muhammadiyah yang diletakkan dasar-dasarnya oleh Ahmad Dahlan, sehingga disebut sebagai gerakan Islam yang berkemajuan. Pertama, Tauhid yang murni, sebagai sumber kekuatan hidup yang membentuk manusia berjiwa merdeka. Kedua, Memahami Al Quran dan As Sunnah secara mendalam, untuk mendapatkan kemudahan, kelapangan dan keterbukaan dalam beragama. Ketiga, Melembagakan amal saleh yang fungsional dan solutif, sebagai pancaran iman yang sempurna dan untuk merefleksikan ajaran Islam yang memberikan rahmat / kasih sayang bagi seluruh alam semesta (rahmatan lil 'alamin). Keempat, berorientasi kekinian dan masa depan, dalam arti memahami dengan baik realitas kekinian untuk merangcang masa depan yang lebih baik. Kelima, bersikap toleran, moderat dan suka bekerja sama, sehingga Muhammadiyah mudah diterima di mana-mana. ${ }^{43}$

Gadamer lebih jauh menyatakan bahwa pemahaman bersifat historikal. Artinya, masa lalu berpengaruh secara aktif pada masa kini. Masa kini dapat dilihat dan dipahami dengan baik hanya lewat pencermatan terhadap konsep-konsep yang diwarisi dari masa lalu. Pendeknya, pemahaman terhadap masa lalu, menurut Gadamer telah memunculkan konsep "kesadaran menyejarah", yakni kesadaran pada diri manusia bahwa sejarah senantiasa bergiat untuk mencipta bagi masa depan. Dengan kata lain, kesadaran menyejarah mencakup suatu kesadaran untuk memikul tanggung jawab guna melakukan perbaikan atau perubahan dalam masyarakat sehingga mempunyai masa depan yang lebih baik.

Ahmad Dahlan, menurut kesaksian Syuja', merupakan seorang alim yang sudah merasa dan mengaku bahwa dirinya telah menempati posisi dan kursi ulama yang harus mempunyai tanggung jawab besar atas masyarakatnya di mata Tuhan, menyadari betul akan baik dan buruk, serta sesat dan benarnya pengamalan agama umat Islam. ${ }^{44}$ Dengan kesadaran yang menyejarah itulah, Ahmad Dahlan terpanggil untuk menyelamatkan umat Islam dari kesesatan, mengentaskan umat Islam dari kondisi kemiskinan, kebodohan dan ketrebelakangan, serta memberikan pencerahan dengan cara mendirikan persyarikatan Muhammadiyah. Arah yang dituju oleh Ahmad Dahlan adalah umat Islam di masa depan yang lebih baik, beriman, cerdas, menguasai ilmu pengetahuan, teknologi dan seni (IPTEKS), berakhlak mulia, dan tentu saja lebih beradab dan berjaya.

\footnotetext{
${ }^{42}$ Baca dalam K.H. Syuja', op. cit., hlm. 29 -30.

${ }^{43}$ Ibid. hlm. x - xxiii.

${ }^{44}$ Ibid. hlm. 30.
} 


\section{PENUTUP}

Dengan mengikuti pendekatan hermeneutik dari Gadamer, akhirnya dapat disimpulkan bahwa Ahmad Dahlan adalah tokoh ulama yang benar-benar memiliki pemahaman mengenai kondisi masyarakatnya, yakni umat Islam, sebagai hasil interaksi antara pengetahuan masa lalu dengan realitas masa kini ketika Ahnad Dahlan hidup. Pemahaman Ahmad Dahlan mengenai kondisi umat Islam yang diliputi oleh kemiskinan, kebodohan dan keterbelakangan, selain berasal dari pengalaman juga dari partisipasi Ahmad Dahlan sebagai ulama yang peka terhadap kondisi umat Islam. Ahnad Dahlan memiliki pemahaman yang kuat terhadap tradisi umat Islam yang diwarnai baik oleh kultur Islam-sinkretis maupun kultur Islamtradisional. Namun, berbeda dengan ulama lain yang larut dalam tradisi, Ahmad Dahlan justru berkemauan kuat untuk mengubah tradisi tersebut agar sesuai dengan tuntunan agama Islam.

Sebelum mendirikan Muhammadiyah, selain memahami realitas kondisi dan tradisi umat Islam sebagaimana diungkap di atas, dalam perspektif hermeneutik, Ahmad Dahlan terlibat dan terbuka dalam menerima gagasan-gagasan pembaruan Islam dari para ulama pembaru terutama Ibnu Taymiyah, Muhammad ibnu Abdul Wahhab dan Muhammad Abduh. Setelah mendirikan Muhammadiyah, Ahmad Dahlan juga terlibat dan terbuka dalam berinteraksi dengan berbagai kalangan guna mendapatkan donasi bagi kelangsungan eksistensi dakwah Muhammadiyah, mulai dari politisi, birokrat, pegawai kereta api hingga pegawai irigasi. Beliau juga terbuka untuk berdialog dengan para agamawan non-muslim, khususnya dari kalangan Katholik.

Ahmad Dahlan menjadi tokoh yang terpanggil dengan kesadaran yang menyejarah dan keberanian memikul beban untuk melakukan perbaikan dan perubahan atas kondisi umat Islam melalui gerakan Muhammadiyah yang didirikannya. Kesadaran menyejarah pada diri Ahmad Dahlan berangkat dari sifat dan tabiat beliau yang kuat dan teguh pendirian, serta berani untuk mendobrak dan melawan tradisi. Sementara keberanian Ahmad Dahlan untuk memikul beban tanggung jawab dakwah amar ma'ruf dan nahi munkar ditopang oleh kesadaran beliau sebagai keturunan ulama besar Wali Sanga, yakni Sunan Giri. Beliau adalah reformer Islam sejati.

\section{DAFTAR PUSTAKA}

Abdullah, M. Amin Abdullah, 2000, “Muhammadiyah's Experience in Promoting A Civil Society", dalam Profetika, Jurnal Studi Islam, Vol. 2, No. 1 Januari 2000, (Surakarta: Program Magister Studi Islam Universitas Muhammadiyah Surakarta).

Asrofie, M. Yusron, 2005, Kyai Haji Ahmad Dahlan Pemikiran dan Kepemimpinannya, (Yogyakarta: MPK-SDI PP Muhammadiyah).

Baidhawy, Zakiyuddin dan Azaki Khoiruddin. 2017. Etika Muhammadiyah dan Spirit Peradaban. Yogyakarta: Suara Muhammadiyah. 
Burhani, Ahmad Najib, 2010, Muhammadiyah Jawa, terjemahan Izza Rohman Nahrowi, (Jakarta: Al Wasat).

Gibb, H.A.R., 1993, Aliran-aliran Moderen dalam Islam, terjemahan Machnun Husein, (Jakarta: Citra Niaga Rajawali Pers).

Hadjid, K.R.H. 2005, Pelajaran KHA Dahlan 7 Falsafah Ajaran dan 17 Klompok Ayat AlQuran, penyunting Budi Setiawan dan Arief Budiman Ch. (Malang: UMM Press),

Kuntowijoyo, 1985, "Muhammadiyah dalam Perspektif Sejarah", dalam M. Amien Rais, dkk. (ed.), Pendidikan Muhammadiyah dan Perubahan Sosial (Yogyakarta : PLP2M).

Liddle, R. William, 1996, Leadership and Culture in Indonesian Politics, (Sydney: Allen \& Unwin),

Ma'arif, Ahmad Syafii, 1987, Islam dan Masalah Kenegaraan Studi tentang Percaturan dalam Konstituante (Jakarta : LP3ES).

Ma'arif, Ahmad Syafii, 2000, "Revitalisasi Ideologi Gerakan Muhammadiyah," dalam Edy Suandi Hamid, M. Dasron Hamid dan Sjafri Sairin (penyunting), Rekonstruksi Gerakan Muhammadiyah pada Era Multiperadaban (Yogyakarta: UII Press).

Mulkhan, A. Munir, 2010, Pesan dan Kisah Kiai Ahmad Dahlan Dalam Hikmah Muhammadiyah, (Yogyakarta: Suara Muhammadiyah).

Noer, Deliar, 1990, Gerakan Moderen Islam di Indonesia 1900-1942, (Jakarta: LP3ES).

Palmer, Richard E. Palmer, 2005, Hermeneutika Teori Baru Mengenai Interpretasi. Terjemahan Musnur Hery dan Damanhuri Muhammad, Cetakan Kedua, (Yogyakarta: Pustaka Pelajar).

Poespoprodjo L. W., 2004, Hermeneutika, (Bandung: Pustaka Setia).

Saidi, Acep Iwan Saidi, 2008, "Hermeneutika, Sebuah Cara untuk Memahami Teks," dalam Jurnal Sosioteknologi Edisi 13 Tahun 7, April 2008.

Salam, Junus, 2009, K.H. Ahmad Dahlan Amal dan Perjuangannya, (Jakarta: Al Wasat).

Shihab, Alwi, 1997, Islam Inklusif, (Bandung: Mizan, 1997).

Shihab, Alwi, 1998, Membendung Arus Respons Gerakan Muhammadiyah terhadap Penetrasi Kristen di Indonesia, (Bandung: Mizan).

Soetrisno, Eddy, dan Elizabeth Tara (editor), 2001, Buku Pintar 100 Tokoh Pahlawan Nasional dan Sejarah Perjuangannya, (Jakarta: Ladang Pustaka dan Intimedia).

Sucipto, Hery, dan Nadjamuddin Ramly, 2005, Tajdid Muhammadiyah dari Ahmad Dahlan hingga A. Syafii Maarif (Jakarta: Grafindo Khazanah Ilmu).

Suwarno, 2010, Relasi Muhammaiyah, Islam dan Negara (Kontribusi Muhammadiyah dalam Perspektif Sejarah), (Yogyakarta: Pustaka Pelajar).

Syuja', K.H., 2009, Islam Berkemajuan Kisah Perjuangan K.H. Ahmad Dahlan dan Muhammadiyah Masa Awal, (Yogyakarta: Al-Wasat). 